\title{
Banco Palmas: inclusão e desenvolvimento local
}

\author{
Palmas Bank: inclusion and local development
}

\section{Banque Palmas: l'inclusion et le développement local}

\author{
Banco Palmas: inclusión y desarrollo local \\ Nicole Cerci Mostagi ${ }^{1}$ \\ Lilian de Lima Pires ${ }^{1}$ \\ Chayne de Lima Pereira Mahnic ${ }^{2}$ \\ Luís Miguel Luzio dos Santos ${ }^{1}$
}

Recebido em 07/07/2017; revisado e aprovado em 21/02/2018; aceito em 26/02/2018

DOI: http://dx.doi.org/ 10.20435/inter.v0i0.1653

\begin{abstract}
Resumo: Este trabalho objetiva analisar o surgimento e a trajetória do Projeto Palmas, sua moeda social, seus avanços e limitações. Utilizando abordagem qualitativa, buscou-se apresentar as especificidades do Banco Comunitário Palmas e suas implicações no contexto em que está inserido. Os resultados indicam a importância do Banco Palmas e da moeda social circulante como mecanismo de empoderamento local e impulso para a geração de trabalho e renda para as populações mais fragilizadas.
\end{abstract}

Palavras-chave: Banco Palmas; economia solidária; banco comunitário; microcrédito.

Abstract: This paper aims to analyze the emergence and trajectory of the Palmas Project, its social currency, results and limitations. Using a qualitative approach, we sought to present the specificities of the Palmas Community Bank and its local implications. The results indicate the importance of the Palmas Bank and its social currency as a mechanism of local empowerment and an impulse to generate work and income for the most vulnerable populations.

Keywords: Palmas Bank; solidarity economy; community bank; microcredit.

Résumé: Ce travail a pour but d'analyser l'émergence et la trajectoire du Palmas projet, sa monnaie sociale, ses progrès et ses limites. En utilisant une approche qualitative, nous avons essayé de présenter les spécificités de la Banque communautaire Palmas et ses implications dans le contexte dans lequel il apparaît. Les résultats indiquent l'importance de la Banque Palmas et monnaie sociale en tant que mécanismes de l'autonomie locale et conduisent à générer des emplois et des revenus pour les populations les plus vulnérables.

Mots-clés: Banque Palmas; l'économie solidaire; banque communautaire; microcrédit.

Resumen: Este trabajo objetiva analizar el surgimiento y la trayectoria del Proyecto Palmas, su moneda social, sus avances y limitaciones. Utilizando un enfoque cualitativo, se buscó presentar las especificidades del Banco Comunitario Palmas y sus implicaciones en el contexto en que está inserto. Los resultados indican la importancia del Banco Palmas y de la moneda social circulante como mecanismos de empoderamiento local e impulso para la generación de trabajo y renta para las poblaciones más fragilizadas.

Palabras clave: Banco Palmas; economía solidaria; banco comunitário; microcrédito.

\section{INTRODUÇÃO}

Não há nenhuma sociedade, em qualquer momento histórico, em que se observe uma repartição de riqueza que possa ser razoavelmente considerada como igualitária, ou seja, onde a metade mais pobre da população detenha parte considerável da propriedade do capital (PIKETTY, 2014). A desigualdade global, no entanto, já atingiu novos extremos. O 1\% da população mais rica do mundo detém mais capital que todo o restante do planeta (CREDIT SUISSE, 2016). A riqueza média de cada adulto enquadrado nessa parcela mais rica é mais de 300 vezes mais elevada que a de uma pessoa que integra os $90 \%$ mais pobres (OXFAM, 2016). Assim, em vez de construir

\footnotetext{
${ }^{1}$ Universidade Estadual de Londrina (UEL), Londrina, Paraná, Brasil.

${ }^{2}$ Universidade Federal de Santa Catarina (UFSC), Florianópolis, Santa Catarina, Brasil.
} 
uma economia que beneficie toda a humanidade, foi constituída uma economia que beneficia uma pequena parcela da população mundial.

De acordo com Sen (2010), vive-se hoje em um mundo de privações, destruição e opressão, com problemas novos e antigos ocorrendo simultaneamente, como a fome coletiva e crônica, a transgressão de liberdades políticas básicas e as ameaças cada vez maiores ao ambiente e à sustentabilidade econômica e social em âmbito planetário. As crises enfrentadas neste tempo despertam a necessidade de repensar o modelo hegemônico de desenvolvimento e considerar formas alternativas ao pensamento dominante de crescimento econômico a qualquer preço.

Nesse contexto, algumas possibilidades de inclusão social podem ser encontradas na literatura, como a economia solidária apresentada por Singer (2002). Para o autor, diferentemente da economia clássica, a economia solidária se propõe a atuar prioritariamente em favor das pessoas e do meio ambiente, defendendo um modelo socioeconômico mais equitativo, redistributivo e sustentável. "A solidariedade na economia só pode se realizar se ela for organizada igualitariamente pelos que se associam para produzir, comercializar, consumir ou poupar. A chave dessa proposta é a associação entre iguais em vez do contrato entre desiguais" (SINGER, 2002, p. 9). A economia solidária se desdobra numa infinidade de experiências, tais como cooperativas, associações mutualistas, lojas de comércio justo, bancos comunitários, entre outros (LUZIODOS-SANTOS, 2014).

Este estudo concentra-se nos bancos comunitários, especificamente no Banco Palmas. Os bancos comunitários podem ser definidos como serviços financeiros solidários, constituídos de forma associativa e comunitária, direcionados para a geração de trabalho e renda no âmbito da reorganização das economias locais, com base nos princípios de economia solidária (LAVILLE, 2010). O estudo dos bancos comunitários, como o Banco Palmas, é relevante por apresentar organizações alternativas ao modelo tradicional capitalista que se revelam capazes de contribuir para a mitigação de alguns problemas sociais, principalmente em âmbito local.

O Banco Palmas foi o primeiro banco comunitário brasileiro, fundado em janeiro de 1998, pela Associação dos Moradores do Conjunto Palmeiras (ASMOCONP), um bairro com 30.000 habitantes, localizado no sul de Fortaleza, Ceará, no nordeste do país. O intuito da criação do banco foi o de implementar ações de desenvolvimento local e de inclusão social, as quais conferiram ao banco o motivo por ser considerado uma das principais experiências de economia solidária no Brasil. Desse modo, esta pesquisa tem como objetivo compreender o surgimento e a trajetória do banco comunitário Palmas no Brasil, sua moeda social, seus resultados e limitações. O artigo contará, num primeiro momento, com uma revisão bibliográfica sobre desigualdades e as possibilidades de inclusão social. Posteriormente abordará os conceitos de economia solidária, banco comunitário e microcrédito. Em seguida serão apresentados os procedimentos metodológicos e os resultados da pesquisa, culminando, por fim, nas considerações finais.

\section{DESIGUALDADES E POSSIBILIDADES DE INCLUSÃO SOCIAL}

As desigualdades sociais têm crescido vertiginosamente. Os hiper-ricos passaram a influenciar cada vez mais o controle da economia e da política em âmbito global (POCHMANN, 2015). O sistema socioeconômico vigente tem a capacidade de produzir muitos bilionários, mas é incapaz de proporcionar uma vida economicamente mais igualitária para todos. O que se nota é o agravamento de todos os problemas, o que impulsiona a humanidade para cada vez mais situações catastróficas. 
Piketty (2014) observa que a história da repartição de riqueza nunca deixou de ser extremamente política, o que impossibilita sua restrição aos mecanismos puramente econômicos. Para o autor (PIKETTY, 2014, p. 27), “[...] a história da desigualdade é moldada pela forma como os atores políticos, sociais e econômicos enxergam o que é justo e o que não é, assim como pela influência relativa de cada um desses atores e pelas escolhas coletivas que disso decorrem". Ou seja, a desigualdade é decorrente da combinação do jogo de forças de todos os atores envolvidos. Como essa história é construída depende de como as sociedades percebem as desigualdades e que formatos de políticas e instituições adotam para avaliá-las e transformá-las (PIKETTY, 2014).

No Brasil, ao longo da história, foram geradas renda e riquezas capazes de proporcionar impactos significativos nas condições de vida de grande parcela da população. Todavia a maior parte da riqueza existente tende a ser apropriada de forma concentrada pela elite. Por outro lado, a ideia de naturalização da pobreza ganha força, e a responsabilidade pelos problemas decorrentes da pobreza passa a recair sobre os sujeitos que se encontram nessa condição, valorizando-se cada vez mais a meritocracia e os feitos individuais, pensamento típico do discurso neoliberal.

Frequentemente, as medidas direcionadas ao enfrentamento da situação de pobreza ainda se restringem aos programas e políticas sociais, planejados e implantados verticalmente, sem a participação dos maiores interessados: as classes populares. A ganhadora do Prêmio Nobel da economia, Elinor Ostrom (2009), desenvolveu suas pesquisas em torno dos bens comuns e comprovou as vantagens da apropriação e provisão de recursos comuns adaptados às condições locais e às escolhas coletivas, considerando a força da participação no processo de tomada de decisão.

Ainda que, diante de um mundo globalizado, ações mundializadas sejam imprescindíveis, Sachs (2006) destaca a importância do desenvolvimento local, considerando que é no espaço regional que se pode fazer a diferença, por meio de contribuições efetivas para um maior equilíbrio econômico, social e ambiental, estabelecendo maior proximidade entre os atores e simetria nas relações. Para tal, são necessários avanços no plano democrático, com protagonismo mais intenso das comunidades locais, para desenhar estratégias para um desenvolvimento que seja simultaneamente sustentável, includente, equitativo e que preserve a cultura regional e enriqueça as relações comunitárias.

Há de se atentar para a dimensão política da pobreza, os processos históricos de destituição de poder da população submetida a essa condição e a falta de representação desse contingente nas várias esferas de decisão do Estado. Diante disso:

A construção de diferentes formatos associativos como meio de enfrentamento coletivo dos problemas sociais e ambientais tem sido uma das alternativas encontradas pelos trabalhadores e produtores autônomos e familiares, nas áreas urbanas e rurais, para viabilizar atividades de produção, de prestação de serviços, de crédito, de comercialização e de consumo, já que nem o Estado nem as empresas oferecem soluções a essas necessidades, pelo menos no médio prazo. (OLIVEIRA; SILVA, 2012, p. 278).

Iniciativas como a citada buscam promover alternativas ao reducionismo economicista e proporcionar novas opções de sociabilidade. Além de buscar o bem-estar dos indivíduos e das coletividades, iniciativas com base em um formato associativo aliadas aos princípios da economia solidária podem trazer soluções concretas para situações sociais consideradas insatisfatórias (AZEVEDO; SILVA; MALAFAIA, 2011). 


\subsection{Economia solidária}

A economia solidária pode ser definida como a junção de atividades econômicas geridas democraticamente como resposta aos problemas sociais, em que os interesses humanos prevalecem sobre os interesses materiais e econômicos (LAVILLE, 2010). Embora a economia solidária tenha sua origem vinculada à tradição cooperativista clássica, ela avança em novas perspectivas por ser:

[...] um sistema socioeconômico aberto, amparado nos valores da cooperação e da solidariedade no intuito de atender às necessidades e aos desejos materiais e de convivência, mediante mecanismos de democracia participativa e de autogestão, visando à emancipação e ao bem-estar individual, comunitário, social e ambiental. (LUZIO-DOS-SANTOS, 2014, p. 60).

Em vez de fazer cumprir uma cultura de competição e acúmulo, na perspectiva da economia solidária busca-se criar culturas e comunidades de cooperação e relacionamentos de apoio mútuo e solidariedade. Em lugar de estruturas centralizadas de controle, a economia solidária tende a uma responsabilidade compartilhada e diretamente democrática. Em vez de impor uma única monocultura global, busca-se fortalecer a diversidade de culturas e ambientes locais. Ao invés de priorizar o lucro, os princípios da economia solidária se baseiam em um compromisso mais amplo com a justiça social, econômica e ambiental (MILLER, 2009).

Cabe ressaltar que priorizar a solidariedade e a cooperação ao invés da individualidade e da competição não infere abandonar a necessidade da lógica de mercado. O debate centra-se no modelo de mercado mais adequado, levando em consideração a inclusão social, o bem comum e a dignidade humana. Desse modo, a economia solidária deve buscar disputar espaço dentro dos mercados convencionais, visando ao seu crescimento e desenvolvimento. Ela "[...] só se tornará uma alternativa superior ao capitalismo quando puder oferecer a parcelas crescentes da população oportunidades concretas de autossustento, usufruindo o mesmo bem-estar médio que o emprego assalariado proporciona" (LUZIO-DOS-SANTOS, 2014, p. 77).

Mesmo com todas as suas limitações, Dowbor (2008) argumenta que mecanismos econômicos como a economia solidária, do ponto de vista político, constituem um grande avanço em direção a algo que se aproxima de processos democráticos.

\subsection{Banco comunitário}

Os bancos comunitários podem ser considerados como experiências de economia solidária. Duas razões revelam que o banco comunitário é um tipo de empreendimento distinto - a hibridação de diferentes fontes de financiamento (moeda social, crédito para produção, empréstimos a juros subsidiados, entre outros) e a construção conjunta de oferta e demanda. Trata-se de uma instituição geralmente operada de forma local, focada no atendimento às necessidades dos negócios da população do entorno, assegurando o acesso a microcrédito. São administradas por cidadãos locais com a finalidade de alavancar a economia e a melhoria das condições de vida da população (AGHION; MORDUCH, 2005; DALEY-HARRIS, 2005).

Os bancos comunitários são experiências orientadas para combater as causas estruturais da desigualdade, defendendo uma posição mais política e menos funcional, afirmando seu compromisso de solidariedade e concebendo suas práticas como uma nova forma de ação coletiva e intervenção pública (LAVILLE, 2010). Eles atuam para promover o desenvolvimento 
de territórios mais pobres, por meio do fomento à formação de redes locais de produção e consumo.

O estabelecimento das regras econômicas leva em conta a voz daqueles que geralmente são excluídos pelas relações de poder de uma economia dominada pela lógica de grandes grupos: mulheres, classes mais baixas, pequenos produtores etc. Desde o momento em que as atividades econômicas são estabelecidas como um meio ao serviço de objetivos relacionados à solidariedade democrática, a produção de bens e serviços obedece a outra lógica: não é decidida de acordo com as perspectivas de lucro, mas de acordo com a adequação ao bem comum (LAVILLE, 2010).

Uma das principais iniciativas dos Bancos Comunitários é o uso de sistemas de moeda social (particularmente aqueles que têm uma capacidade endógena para ajustar a oferta monetária social, em resposta a transações realizadas por seus participantes) e podem proporcionar maior eficácia a uma política de depósitos compulsórios diferenciados implementada de acordo com as necessidades de crédito. Assim, contribuem para uma melhor distribuição do fornecimento de crédito dentro de um sistema financeiro nacional e, consequentemente, para menores custos de crédito bancário para trabalhadores independentes e micro e pequenos empreendedores dentro da economia local (FREIRE, 2009). As moedas sociais são projetadas para desenvolver relações interpessoais, constituindo espaços de confiança onde as regras são negociadas, o que permite que as capacidades locais sejam valorizadas para além das que são mobilizadas pela produção mercantil (LAVILLE, 2010).

Ao incentivar as pessoas a produzirem e consumirem na própria comunidade, o banco comunitário busca reorganizar a economia local, criando um grupo de "prossumidores", articulando-se em rede, comprando e vendendo um para o outro, criando múltiplas conexões econômicas e organizando lutas sociais por direitos e políticas públicas (INSTITUTO BANCO PALMAS, s.d.). O desafio é definir políticas que os apoiem por causa de suas contribuições, não só nos âmbitos econômico e social, mas também no plano político (LAVILLE, 2010).

\subsection{Microcrédito}

O microcrédito designa geralmente empréstimos de pequeno valor concedidos a grupos ou indivíduos a partir de fundamentos solidários em que o objetivo não é a maximização do lucro do banco, mas o impulsionamento de atividades econômicas, o desenvolvimento comunitário, nomeadamente impulsionando o autoemprego, a formação de cooperativas ou de pequenos negócios locais diante de uma condição de pobreza e desemprego (SERVET, 2006).

Concebido como parte da luta contra a pobreza, o seu rápido sucesso se deu, em parte, por se tratar de uma ferramenta simples, oferecida como uma solução para grupos desfavorecidos (LAVILLE, 2010). Muhammad Yunus, economista e prêmio Nobel da Paz de 2006, é um dos pioneiros em trabalhar com concessão de microcrédito e empreendedorismo em larga escala para a redução da miséria. Em 1976, ele fundou o Banco Grameen, em Bangladesh, que realiza empréstimos de forma mais simples (YUNUS, 2008). O Banco Grameen foi concebido por Yunus em parceria com alunos e professores da Universidade de Chittagong. A experiência se iniciou com o fornecimento de pequenos empréstimos sem as requisições e garantias convencionais exigidas pelos bancos tradicionais.

Em 1983, o Grameen se tornou um banco oficial e passou a conceder crédito para pessoas em situação de pobreza em Bangladesh, sobretudo para mulheres da zona rural. A preferência 
pelo público feminino para a concessão dos empréstimos ocorreu em razão do contexto de exploração e pobreza local, que atinge particularmente as mulheres. A experiência buscou proporcionar a independência financeira de pessoas em situação de maior vulnerabilidade, que eram impedidas de ter acesso ao crédito de bancos tradicionais por falta de bens e fiadores para garantir o empréstimo (YUNUS, 2008).

Para Braga e Toneto Júnior (2000), o microcrédito vem sendo considerado um dos principais instrumentos das políticas de geração de trabalho e renda no mundo. Diversas experiências internacionais têm comprovado que é possível criar arranjos contratuais que viabilizem o crédito a pequenos empreendimentos. Além do Banco Grameen, diversas instituições de microcrédito no mundo confirmam a viabilidade desse tipo de empreendimento. Pode-se destacar o Banco Rakyaí, na Indonésia, criado no início dos anos 1970, o Programa de Empresa Rural do Quênia, criado em 1984, e o Banco Solidário S.A da Bolívia, criado em 1992 (BRAGA; TONETO JúNIOR, 2000).

\section{PROCEDIMENTOS METODOLÓGICOS}

A presente pesquisa caracteriza-se como qualitativa, que "[...] trabalha com o universo de significados, motivos, aspirações, crenças, valores e atitudes, o que corresponde a um espaço mais profundo das relações" (MINAYO, 2001, p. 14). Ou seja, se preocupa com o aprofundamento da compreensão de um grupo social, de uma organização. Ademais, o método apoia o uso de uma diversidade de fontes de dados, o que possibilita o aprofundamento do estudo. A experiência do Banco Palmas foi selecionada, por ser o primeiro Banco Comunitário no Brasil e pelos seus resultados sociais e econômicos.

A estratégia de investigação escolhida foi o estudo de caso, que é definido por Yin (2010, p. 39-40) como "[...] uma investigação empírica que investiga um fenômeno contemporâneo em profundidade e em seu contexto da vida real, especificamente quando os limites entre o fenômeno e o contexto não são claramente evidentes". Este tipo de estudo pode ser caracterizado como descritivo, pois busca apresentar um relato detalhado de um fenômeno social contemplando, por exemplo, sua configuração, estrutura, atividades, modificações ao longo do tempo e relacionamento com outros fenômenos (YIN, 2010).

Quanto aos instrumentos de coleta de dados, optou-se pelo levantamento documental e entrevistas. O levantamento dos documentos se deu em livros, revistas científicas e dissertações; alguns dados sobre o Banco Palmas também foram consultados no seu website, na internet. Após a organização desses dados, foi analisada uma entrevista feita por Nascimento, em 2011, com a coordenadora do banco Palmas na época.

Em um segundo momento, foram realizadas entrevistas semiestruturadas, que são utilizadas "[...] para recolher dados descritivos na linguagem do próprio sujeito, possibilitando ao investigador desenvolver uma ideia sobre a maneira como os sujeitos interpretam aspectos do mundo" (GODOY, 2006, p. 134). As entrevistas foram realizadas com dois membros atuais da equipe do Banco Palmas, um dos fundadores e um agente de desenvolvimento; suas contribuições estão referenciadas, ao longo dos resultados, como Fundador (2017) e Agente de Desenvolvimento (2016). As entrevistas foram realizadas respectivamente em 2016, por telefone e e-mail e, em 2017, via teleconferência por Skype. Essas entrevistas foram fundamentais para compreender melhor a organização, porque trazem contribuições de fonte primária, com dados atuais da realidade do Banco Palmas. 


\section{BANCO PALMAS}

Fortaleza, a capital do estado do Ceará, é um dos principais destinos turísticos no Brasil. Com uma população de 2,5 milhões, a cidade recebe cerca de dois milhões de visitantes por ano, atraídos principalmente pelas praias. A moderna infraestrutura turística está localizada ao longo da área costeira, na parte mais rica da cidade. No entanto este não foi sempre o caso. Até os anos 1970, parte dessa região foi ocupada por favelas. Em 1973, com o crescimento do turismo e do processo de valorização do solo urbano, o município iniciou uma política destinada a conduzir os moradores das favelas para fora dessa área.

Como afirma o fundador do Banco Palmas, "o conjunto Palmeiras era uma grande favela até 1997, nós morávamos na beira-mar em 1973, fomos expulsos pela prefeitura para urbanizar Fortaleza, viemos aqui para a região, fomos trazidos para uma região completamente sem infraestrutura urbana" (FUNDADOR, 2017). Essa política urbana foi executada por uma agência chamada Fundação para o Serviço Social de Fortaleza e consistiu basicamente na transferência de habitantes de baixa renda dos distritos desenvolvidos centrais para as áreas suburbanas e subdesenvolvidas da cidade (JAYO; POZZEBON; DINIZ, 2008).

Foi nesse contexto que o Conjunto Palmeiras surgiu, em 1973, como resultado do deslocamento de 1.500 famílias de baixa renda que não eram bem-vindas nas áreas turísticas. Os habitantes foram forçados a abandonar as suas habitações nas favelas centrais e foram transferidos para uma área localizada a $22 \mathrm{~km}$ de distância da faixa litorânea. Ao alinhar a cidade de forma mais estreita com o turismo, a política urbana negligenciou os problemas estruturais e sociais que afetaram os moradores realocados. A nova área destinada a eles estava distante de postos de trabalho e escolas, com acesso precário ao transporte urbano e sem abastecimento de água, saneamento ou eletricidade (JAYO; POZZEBON; DINIZ, 2008).

Segundo o Agente de Desenvolvimento (2016), dentro de um período muito curto de tempo, o Conjunto Palmeiras tinha se transformado em uma favela periurbana de 30.000 habitantes, muito precária e com desatenção das autoridades públicas, com pouca infraestrutura. Como é típico das favelas brasileiras, a comunidade cresceu em um contexto desprovido de uma infraestrutura básica ou serviços sociais e em meio a condições de vida extremamente precárias e níveis muito baixos de desenvolvimento humano. Para tentar mitigar essa situação, em 1981, foi fundada, no bairro a Associação dos Moradores do Conjunto Palmeiras (ASMOCONP), uma iniciativa dos líderes da comunidade local. Inicialmente apoiada por setores progressistas da Igreja Católica e por ONGs locais e internacionais, a ASMOCONP imediatamente começou a trabalhar para uma série de melhorias na infraestrutura local.

Até o final da década de 1990, como resultado de quase duas décadas de esforço contínuo, a "ex-favela" foi finalmente urbanizada (JAYO; POZZEBON; DINIZ, 2008). De acordo com o Fundador (2017), os moradores empenharam-se por mais de 20 anos para a urbanização do bairro, organizando-se por meio de mutirões comunitários que viabilizaram o acesso a água, energia elétrica e saneamento.

Apesar dessas melhorias urbanas, as condições socioeconômicas dos membros da comunidade não melhoraram no mesmo ritmo. Pelo contrário, de acordo com o fundador e líder comunitário do bairro, os moradores começaram a vender seus barracos e se mudar para outras favelas. Isso aconteceu porque, na época, o estado do Ceará enfrentava secas, o que intensificava a fome e a miséria, levando a população a vender suas moradias e deslocar-se para locais mais precários (FUNDADOR, 2017). 
Nesse contexto de crise, surge o Banco Palmas, em janeiro de 1998, por uma iniciativa da associação de moradores do bairro, com a ideia de que a produção e consumo local favoreceria o desenvolvimento do território (FUNDADOR, 2017). Segundo o Fundador (2017), o objetivo era estimular o desenvolvimento local com base na produção, comercialização e consumo na própria comunidade, gerando renda e oportunidades para as famílias.

O foco do projeto era a criação de uma "rede de solidariedade" para a integração dos produtores e consumidores locais, de tal forma que a maior parte possível da riqueza local circulasse localmente, permanecendo na comunidade. Em vista disso, "logo após o seu surgimento, criaram-se a moeda comunitária, correspondente bancário, projetos e outros serviços, junto com a multiplicação da metodologia da criação de outros bancos comunitários" (AGENTE DE DESENVOLVIMENTO, 2016). Contrapondo as metodologias dominantes e minimalistas que favorecem resultados individuais e apenas financeiros, o Banco Palmas desenvolveu uma metodologia de microcrédito centrada na geração de renda, riqueza e desenvolvimento social em uma base territorial.

\subsection{Produtos e serviços}

O Banco Palmas é um sistema financeiro solidário que trabalha em quatro pontos da cadeia produtiva local: capital solidário, produção sustentável, consumo solidário e comércio justo. Um banco comunitário "não é um negócio frio, distante, burocratizado, informatizado, e nem é ao mesmo tempo uma bagunça" (FUNDADOR, 2017). O Fundador (2017) complementa dizendo que, apesar de estarem submetidos a órgãos de controle, tribunais de conta e auditorias, o foco permanece na comunidade, na natureza humana e no cuidado com as pessoas. Essa posição alinha-se com a tese de Sachs (2006), que entende a necessidade de se priorizar a produção e o consumo locais, para que os recursos gerados na região sejam, em grande parte, nela reinvestidos, e de se tornarem os atores envolvidos simultaneamente responsáveis e beneficiários dos resultados auferidos.

A gestão do Banco é feita pela Associação dos Moradores do Conjunto Palmeiras e, na grande maioria, seu quadro de pessoal é constituído por moradores voluntários (MELO NETO SEGUNDO; MAGALHÃES, 2003): "a gestão é descentralizada, através de um conselho gestor, composto por 30 pessoas da própria comunidade. Portanto a comunidade é proprietária e faz a gestão do banco", sendo que todos os funcionários são moradores do bairro (FUNDADOR, 2017)

De acordo com Melo Neto Segundo e Magalhães (2003), o Banco Palmas apresenta quatro linhas de crédito. A primeira é o microcrédito concebido para os que não podem acessar as fontes de financiamento oficiais por causa de burocracia, exigências quanto ao fiador, nível de renda, patrimônio e outras normas bancárias. Os créditos cedidos pelo banco comunitário não exigem documentos, nem garantias, pois os próprios vizinhos e moradores do bairro oferecem as informações sobre o tomador do crédito.

O Fundador (2017) pontua que a taxa de juros varia de $1 \%$ a $3 \%$, dependendo do valor emprestado, sendo de $1 \%$ para valores até $\mathrm{R} \$ 5.000,00,2 \%$ entre $\mathrm{R} \$ 5.000,00$ e $\mathrm{R} \$ 10.000,00$ e $3 \%$ para valores acima de $\mathrm{R} \$ 10.000,00$. Com isso, busca-se um equilíbrio a fim de promover a justiça social na concessão dos empréstimos. Também aponta que grupos solidários têm redução na taxa de juros e maior agilidade na aprovação do crédito, pois o objetivo é a priorização do coletivo (FUNDADOR, 2017). 
A segunda linha de crédito é o microcrédito para o consumo, que engloba o Palmacard, cartão de crédito válido apenas para compras no bairro. Cada cartão de crédito tem o valor inicial de $R \$ 20,00$ e pode chegar ao máximo de $\mathbf{R} \$ 100$. Não há pagamento de nenhuma taxa para ter o cartão. A terceira é uma linha de crédito específica para atendimento das mulheres. O Banco Palmas tem financiado a produção de mulheres empreendedoras do bairro, dando prioridade às que se encontram em situação de risco pessoal e social (SILVA JUNIOR; MAGALHÃES; MELO NETO, 2005).

A quarta linha de crédito é destinada a pequenas reformas de moradia e tem o intuito de melhorar as condições de produção. Os que necessitam fazem um orçamento no depósito de construção do bairro e recebem a autorização do banco para receber o material. O pagamento pode ser feito em seis vezes com juros de 1,5\% ao mês. Quanto às garantias de pagamento, ao fazer o cadastro de um futuro tomador de empréstimo, os analistas do Banco Palmas não têm em vista consulta a órgão de restrição ao crédito. A única consulta realizada é uma abordagem aos moradores do bairro, que atestam ou não a confiabilidade do candidato ao crédito. A cobrança do empréstimo baseia-se também nas relações de vizinhança e proximidade, impondo um controle mais social que propriamente econômico (SILVA JUNIOR; MAGALHÃES; MELO NETO, 2005).

\subsection{Moeda social - Palmas}

A moeda social denominada de Palma (Palmares inicialmente) surgiu logo após a fundação do Banco, com o intuito de estimular o desenvolvimento da economia local por meio do consumo no próprio bairro (AGENTE DE DESENVOLVIMENTO, 2016; FUNDADOR, 2017). A moeda social possui cinco características principais: é lastreada em reais, então a quantidade de moeda emitida é a mesma quantidade de reais guardada no Banco; permite câmbio, ou seja, qualquer comerciante pode se dirigir ao banco e trocar as palmas por reais; tem circulação local, funcionando apenas naquela localidade, na comunidade (no caso do Palmas, na região do Conjunto Palmeiras); é uma forma de adesão à rede local, por isso os comerciantes não são obrigados a aceitar a moeda social; por fim, a moeda social tem elementos de segurança, código de barras, infravermelho, número em serial e papel moeda (FUNDADOR, 2017). Na opinião de Sachs (2006), as moedas sociais são instrumentos efetivos para a redução da pobreza na medida em que fortalecem o comércio e as atividades locais e possibilitam um empoderamento das comunidades, já que os recursos do bairro giram no próprio bairro.

De uso exclusivo do Banco Palmas, a moeda social Palma é um dinheiro alternativo, que circula e tem validade apenas no bairro, sendo uma forma de troca alternativa à moeda oficial brasileira. Para o fundador, a utilização da moeda social traz quatro vantagens principais: primeiro, ajuda a desenvolver o bairro, porque o dinheiro circula localmente. A segunda vantagem é que, em caso de sinistro, se for roubado, não tem validade em outros territórios. A terceira vantagem é que, com a moeda social, o empréstimo não tem juros. A quarta vantagem é que alguns comerciantes do bairro dão descontos que variam de $5 \%, 10 \%$ para quem a utiliza em suas compras. Mas em linhas gerais, o grande objetivo da moeda social é estimular que as famílias comprem localmente, criando uma poupança local, gerando mais desenvolvimento, mais emprego e mais renda na comunidade (FUNDADOR, 2017).

Para a Coordenadora do Banco Palmas, a moeda Palma produz riqueza "porque ela cria uma poupança interna. Ela não permite que os recursos (o dinheiro) da comunidade migrem para outros territórios" (NASCIMENTO, 2011, p. 111). O Fundador (2017) indica que, segundo 
uma pesquisa realizada em 1998, no início da operação do Banco, apenas $20 \%$ das pessoas compravam na comunidade. Na última pesquisa realizada pelo Banco, em 2016, esse percentual aumentou para $95 \%$.

Em relação à permissão do Banco Central para o funcionamento da moeda social, a Coordenadora do Banco Palmas alega que ele adotou uma postura de incompreensão no início, inclusive processou o Banco Palmas por esse motivo (NASCIMENTO, 2011). "Aquilo que há 20 anos atrás era criminalizado pelo Estado, hoje está dentro do PPA, o Plano Plurianual do governo federal, tem lá uma estratégia de ampliar os bancos comunitários no Brasil" (FUNDADOR, 2017). Assim, o Banco Central passou a apoiar os bancos comunitários e as moedas sociais nos últimos anos. Para o Agente de Desenvolvimento (2016), atualmente há um posicionamento do Banco Central no sentido de reconhecer que a moeda social traz um benefício maior que o financeiro, estimulando o desenvolvimento social e político na região em que atua.

Segundo Fobe e Vilela (2011, p. 2), as moedas sociais "[...] chamam a atenção pela potencialidade e, ao mesmo tempo, pela desregulamentação absoluta. Não há, no Brasil, marco regulatório algum em se tratando de moedas complementares". Por outro lado, o Fundador (2017) explica que existe uma nota técnica do Banco Central que informa que os Bancos Comunitários não são ilegais e que contribuem para o desenvolvimento do país. Dessa forma, ele pontua que a experiência do Banco Palmas se apresenta como um novo formato de banco e de finanças, servindo de modelo para outras iniciativas.

\subsection{Principais limitações e resultados}

Quanto aos desafios enfrentados pelo Banco Palmas, o Fundador (2017) aponta que o principal deles é não perder sua missão original ao passo em que busca o aperfeiçoamento dos processos. Além disso, ele pontua que o Banco Comunitário precisa acompanhar as mudanças e aumentar a participação e integração dos moradores, assim como trabalhar para a criação de novos bancos comunitários. Outro grande desafio do momento diz respeito à transformação dos bancos manuais, analógicos, em bancos digitais. Segundo o Fundador (2017), foi implantada uma plataforma digital, que pode ser operada por celular, internet banking e computadores, o que, de acordo com sua perspectiva, irá gerar grandes possibilidades de crescimento e escala.

Por outro lado, Singer (2002) alerta para o risco de que o crescimento dos empreendimentos de base solidária pode vir acompanhado de redução das características originais e se converter à lógica capitalista tradicional em que o resultado financeiro da própria instituição se sobrepõe aos benefícios sociais inicialmente objetivados.

Embora já haja melhorias quanto às políticas públicas pertinentes à economia solidária, ainda há deficiência de integração das políticas governamentais que agem nesse campo, resistência e desconfiança de órgãos públicos e outras instituições atuantes na área por conta de diferenças políticas e ausência de conhecimento sobre o assunto. Entretanto, do ponto de vista não econômico, não material, o bairro está mais organizado, por meio de conselhos populares, associação de mulheres e de jovens; assim, os impactos do Banco Comunitário Palmas certamente extrapolam o âmbito financeiro (FUNDADOR, 2017).

Apesar dos avanços, o Fundador (2017) aponta ainda três grandes limitações enfrentadas pelo Banco Comunitário. Primeiramente, apesar de tantos anos de atuação e da existência de outras experiências estabelecidas no território nacional, ainda não há regulamentação para essas 
instituições. Por não haver um marco regulatório, surge a segunda limitação, o fato de o Banco Palmas não poder captar poupança, o que significa que o banco acaba dependendo do sistema financeiro tradicional, fazendo empréstimos junto aos bancos tradicionais, com taxas de juros elevadas e exigências que divergem em alguns aspectos do propósito do Banco Comunitário. A terceira grande limitação apontada diz respeito à dificuldade em alcançar escala, "hoje, nós somos 113 no Brasil, nossa meta é chegar a 1000 bancos comunitários no Brasil. Haja vista a grande demanda que existe nesse país, metade do povo brasileiro está fora do sistema financeiro, não estão com conta em banco" (FUNDADOR, 2017). Sousa Santos (2002) chama a atenção para a necessidade de se pensar os empreendimentos de base solidária em escala, seja por meio de redes ou articulações diversas que potencializem as iniciativas locais, sob o risco de se comprometer a eficiência necessária à viabilização dessas organizações.

Em contrapartida, os benefícios gerados pelo Banco Palmas, segundo o Agente de Desenvolvimento (2016), consistem na contribuição de seus produtos e ações para o desenvolvimento local, valorização de produtos e pessoas da comunidade, bem como a geração de empregos na comunidade. O Fundador (2017) diz que "o banco ajudou a se organizar, a planejar, a pensar melhor no futuro e, principalmente e sobretudo, não aceitar a pobreza, a miséria, a desigualdade como uma dádiva de Deus, e sim como uma consequência injusta da sociedade". Na visão do Agente de Desenvolvimento (2016), os resultados mais relevantes alcançados foram o reconhecimento da comunidade e de outros meios sociais, a implantação de sistema dos bancos comunitários em outras regiões e o crescimento comercial e social da comunidade (AGENTE DE DESENVOLVIMENTO, 2016).

Segundo o Agente de Desenvolvimento (2016), o Banco Comunitário contribui para a melhoria da qualidade da vida da população, levando a população a se apoderar de um bem criado para a própria comunidade, reconhecendo a importância de se trabalhar em grupo, procurando sempre um benefício social maior. Além disso, para a coordenadora do Banco Palmas, a rede de comércio solidário garante que o dinheiro circule localmente, aumentado as possibilidades de trabalho, emprego, renda e qualidade de vida na comunidade (NASCIMENTO, 2011). Apesar das dificuldades apresentadas em relação à moeda Palma, observa-se que seus benefícios têm impulsionado a circulação dela, fortalecendo a rede de solidariedade comunitária e o avanço do Banco Palmas.

\section{CONSIDERAÇÕES FINAIS}

O Banco Palmas está ajudando a educar e criar consciência na população local, de modo a favorecer o desenvolvimento socioeconômico desse território. Além disso, percebe-se um engajamento político da população, que é favorecido pela valorização da produção e consumo local e pelo fortalecimento da articulação entre os moradores do bairro nas lutas sociais por direitos e políticas públicas pela legitimação de uma rede solidária.

Esta pesquisa revela a importância do Banco Palmas e da moeda social circulante na geração de renda e empregos à população local. Ademais, reforça a importância da economia solidária e popular na mitigação da pobreza. Como é evidenciado por meio das entrevistas, os projetos e ações desenvolvidos pelo Banco Palmas são amplos - vão do microcrédito e da moeda social a outros projetos de empoderamento local - e importantes, pois contribuem para o desenvolvimento humano e do bairro e para a qualidade de vida dos moradores. A criação de 
um sistema econômico paralelo no bairro, por meio de uma linha de crédito alternativo e de instrumentos de incentivos para o consumo local (cartão de crédito e moeda social) desenvolveu novas formas de comercialização solidárias. Sendo assim, o grande mérito do Projeto Palmas é ter conseguido preservar a circulação de recursos da comunidade no comércio local, ocasionando o empoderamento da região onde foi desenvolvido.

Conclui-se que investir em políticas socioeconômicas e alternativas ao capitalismo atual, como é o caso do banco comunitário - Banco Palmas, pode resultar em oportunidades de crescimento e sobrevivência às populações pobres, assim como na melhoria da qualidade de vida, ocorrendo um desenvolvimento local inovador de inclusão social coletiva. Nesse sentido, iniciativas dentro dessa perspectiva são de grande relevância no contexto econômico atual, marcado pelo monopólio de organizações privadas, fundamentadas na maximização dos lucros e exploração dos mais fragilizados. Ainda que seja difícil imaginar forças díspares convivendo dentro das mesmas regras sem que os mais fortes aniquilem os mais frágeis quando estes passam a incomodar ou ampliar as oportunidades de avanços do capital, essas políticas alternativas ganham destaque ao propor iniciativas amparadas em novas ideias de sociabilidade.

O caso do Banco Palmas pode auxiliar na formulação de políticas públicas e na replicação em outros territórios, por meio da metodologia de desenvolvimento de comunidades como a concebida pela ASMOCONP/Banco Palmas. Outro impacto positivo das ações desenvolvidas pelo Banco Palmas está na percepção positiva do Banco no imaginário dos seus parceiros, clientes e beneficiários de seus projetos, que resulta no aumento da capacidade financeira e administrativa de atendimento e no suporte às necessidades da comunidade, benefícios que estão intimamente relacionados com o grau de confiança entre as pessoas e o mecanismo de funcionamento do banco e de sua moeda social.

\section{REFERÊNCIAS}

AGHION, A.; MORDUCH, J. The economics of microfinance. London: MIT Press, 2005.

AZEVEDO, D. B.; SILVA, T. N.; MALAFAIA, G. C. O papel dos stakeholders sociais nas redes solidárias sob a ótica do desenvolvimento sustentável: o caso da Univens. Revista Global Manager, v. 11, n. 1, p. 1-22, 2011.

BRAGA, M. B.; TONETO JÚNIOR, R. Microcrédito: aspectos teóricos e experiências. Análise Econômica, Porto Alegre, RS, v. 18, n. 33, p. 69-86, mar. 2000.

CREDIT SUISSE. Global Wealth Report. 2016. Disponivel em: https://www.credit-suisse.com/corporate/ en/articles/news-and-expertise/the-global-wealth-report-2016-201611.html. Acesso em: 2 abr. 2017.

DALEY-HARRIS, S. State of microcredit summit campaign. Report 2005. Washington, Dec., 2005.

DOWBOR, L Democracia econômica: alternativas de gestão social. Petrópolis, RJ: Vozes, 2008.

FOBE, N. J.; VILELA, R. Moedas sociais - mecanismo de desenvolvimento e desafio multidisciplinar. 2011. Disponível em: https://direitosp.fgv.br/sites/direitosp.fgv.br/files/moedas_sociais_-_narrativa.pdf. Acesso em: 25 fev. 2016.

FREIRE, M. V. Social economy and central banks: legal and regulatory issues on social currencies (social money) as a public policy instrument consistent with monetary policy. International Journal of Community Currency Research, v. 13, p. 76-94, 2009. 
GODOY, A. S. Estudo de caso qualitativo. In: GODOI, C. K.; BANDEIRA-DE-MELLO, R.; SILVA, A. B. (Org.). Pesquisa qualitativa em estudos organizacionais: paradigmas, estratégias e métodos. São Paulo: Saraiva, 2006. p. 115-47.

INSTITUTO BANCO PALMAS. O que é um Banco Comunitário. [s.d.]. Disponível em: http://www. institutobancopalmas.org/o-que-e-um-banco-comunitario/. Acesso em: 22 fev. 2016.

JAYO, M.; POZZEBON, M.; DINIZ, E. H. Microcredit and innovative local development in Fortaleza, Brazil: the case of Banco Palmas. Canadian Journal of Regional Science, v. 32, p. 115-28, 2009.

LAVILLE, J. L. The solidarity economy: an international movement. RCCS Annual Review [Online], n. 2, p. 1-41, 2010.

LUZIO-DOS-SANTOS, L. M. Socioeconomia: solidariedade, economia social e as organizações em debate. São Paulo: Atlas, 2014.

MELO NETO SEGUNDO, J. J.; MAGALHÃES, S. Bairros pobres, ricas soluções: Banco Palmas, ponto a ponto. Fortaleza, CE: Expressão Gráfica, 2003.

MINAYO, M. C. S. (Org.). Pesquisa social: teoria, método e criatividade. Petrópolis, RJ: Vozes, 2001.

MILLER, E. Solidarity economy: key concepts and issues. In: KAWANO, E.; MASTERSON, T. N.; TELLERELSBERG, J. Solidarity economy I: building alternatives for people and planet. Amherst: Center for Popular Economics, 2009. p. 25-42.

NASCIMENTO, A. M. Moeda palma e o desenvolvimento sustentável do conjunto Palmeiras através da economia solidária. 2011. 131 fls, Dissertação (Mestrado Profissional em Economia)- Universidade Federal do Ceará (UFC), Fortaleza, 2011.

OLIVEIRA, N. D. A.; SILVA, T. N. Inovação social e tecnologias sociais sustentáveis em relacionamentos intercooperativos: um estudo exploratório no CREDITAG-RO. Revista de Administração da UFSM, Santa Maria, RS, v. 5, n. 2, p. 277-295, maio/ago. 2012.

OSTROM, E. Governing the commons - the evolution of institutions for collective action. 22. ed. New York: Cambridge University Press, 2009.

OXFAM. Uma economia para o 1\%. 2016. Disponível em: https://www.oxfam.org.br/publicacoes/ sumario_executivo. Acesso em: 2 mar. 2017.

PIKETTY, T. O capital no século XXI. Rio de Janeiro: Intrínseca, 2014.

POCHMANN, M. Desigualdade econômica no Brasil. São Paulo: Ideias \& Letras, 2015.

SACHS, I. Desenvolvimento includente, sutentável e sustentado. Rio de Janeiro: Garamond, 2006.

SEN, A. Desenvolvimento como liberdade. São Paulo: Companhia das Letras, 2010.

SERVET, J.-M. Banquieres et banquiers aux pieds nus. Paris: Odile Jacob, 2006.

SILVA JUNIOR, J. T.; MAGALHÃES, S.; MELO NETO, J. O poder do circulante local: a moeda social no conjunto Palmeira. Fortaleza, CE: Expressão Gráfica, 2005.

SINGER, P. Introdução à economia solidária. São Paulo: Fundação Perseu Abramo, 2002. 
SOUSA SANTOS, B. de (Org.). Produzir para viver: os caminhos da produção não capitalista. Rio de Janeiro: Civilização Brasileira, 2002.

YIN, R. K. Estudo de caso: planejamento e métodos. 4. ed. Porto Alegre, RS: Bookman, 2010.

YUNUS, Muhammad. Um mundo sem pobreza: a empresa social e o futuro do capitalismo. São Paulo: Ática, 2008.

\section{Sobre os autores:}

Nicole Cerci Mostagi: Mestrado em Administração e graduação em Administração pela Universidade Estadual de Londrina (UEL). Atua principalmente com produção acadêmica nos seguintes temas: espaço urbano, gestão urbana, políticas públicas, subjetividade, sustentabilidade. E-mail: nicole_cerci@hotmail.com

Lilian de Lima Pires: Mestrado em Administração pela Universidade Estadual de Londrina (UEL), graduação em Tecnologia em Gestão Pública pelo Instituto Federal do Paraná (IFPR) e graduação em Administração pela Pontifícia Universidade Católica do Paraná (PUC-PR). É estatutário da Prefeitura Municipal de Ibiporã. Tem experiência na área de Administração, com ênfase em Administração Pública. E-mail: lilianpires9@hotmail.com

Chayne de Lima Pereira Mahnic: Doutornda em Administração pelo Programa de Pós-Graduação em Administração da Universidade Federal de Santa Catarina (PPGA-UFSC). Mestrado em Administração e graduada em Administração pela Universidade Estadual de Londrina (UEL). E-mail: chaynemahnic@hotmail.com

Luís Miguel Luzio dos Santos: Pós-Doutorando em Ciências Sociais - Pensamento Complexo; Doutor em Ciências Sociais (PUC-SP); Mestre em Administração (UEL); Graduado em Ciências Econômicas e em Administração (UEL). Professor Associado do Departamento de Administração da Universidade Estadual de Londrina (UEL); Professor do Programa de Mestrado em Gestão e Sustentabilidade (UEL); Autor dos livros: Socioeconomia: Organizações e Solidariedade em Debate. Atlas-Salta; Pautas para Outra Sociabilidade- Eduel; Organizador e Coautor dos livros: Economia Solidária em Londrina e Economia Solidária numa pluralidade de perspectivas. Pesquisador do CNPq, nas áreas: Democracia Econômica, Socioeconomia, Economia Solidária, Sustentabilidade e Políticas Públicas. E-mail: Imig@uol.com.br 